\title{
HEALTH STATIONS.
}

\section{MADEIRA AND THE CANARY ISLANDS.}

For early cases of pulmonary tuberculosis who object to a British Sanatorium, and also for later half-arrested cases who require longer open-air treatment, and again for all those who stand cold badly, the wonderful climate and the facilities for treatment available in the Canaries and Madeira are worth considering. MAdEIRA is a beautiful island, with mountains of 6,00o feet elevation, and having a rainfall of 30 inches, which keeps all green and well wooded. It is warm and sedative at sea-level, and the moisture in the air makes it very equable, $61^{\circ} \mathrm{F}$. in winter, $71^{\circ} \mathrm{F}$. in summer, being the mean daily averages, with a difference of $8^{\circ} \mathrm{F}$., as a rule, only between night and day temperatures. The climate is somewhat relaxing, and tends to keep invalids in a state of repose, which is exactly what many consumptives require. It is an ideal place for a bronchitic case, or for a patient with chronic

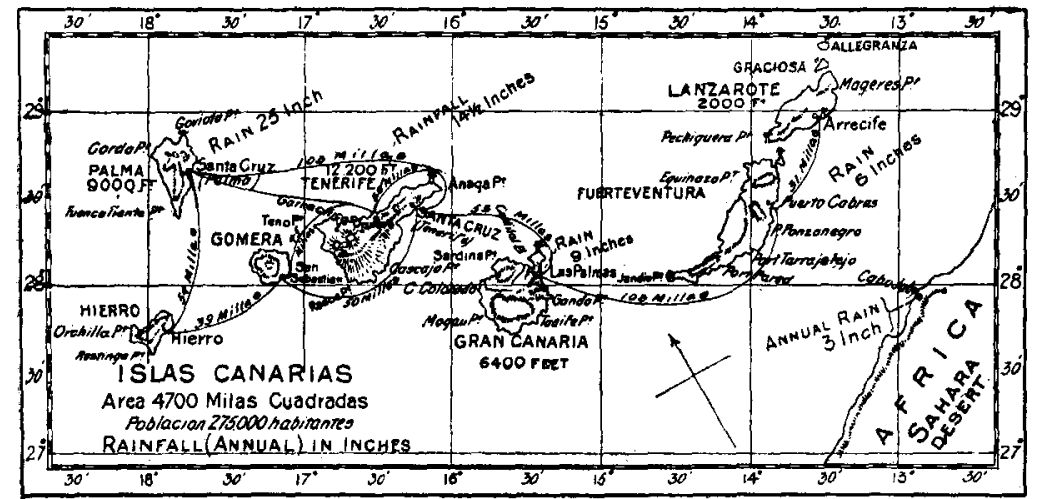

gradually advancing pulmonary tuberculosis. Invalids have gone there for generations, but the accommodation has improved enormously in the last seventeen years. Reid's Palace Hotel, on the West Cliff of Funchal, is practically an open-air sanatorium in its own grounds of several acres, and is quite first class. The cog-wheel railway to the Monte Church has caused three new altitude hotels to be built, supplying a long-felt want in the island. At 2,000 feet, reached by rail in twenty minutes from the shore, a bracing mountain atmosphere is reached, and at this elevation in extensive grounds are the Monte Palace Hotel and Reid's Mount Park Hotel. The Kurhaus Santa Anna is at I,25o feet elevation, and is fitted with electric and carbonic baths, vibration massage, etc., and has a resident physician. These high-altitude hotels are situated in charming scenery and in the pinetree area, and although some cloud and mist may be found there in the winter months, the air is far more tonic and stimulating to a patient 
with early phthisis than the air of Funchal at sea-level. In summer the mountain climate is excellent for open-air treatment at this altitude. It is, however, even better at 4,000 feet, but here one must camp out in tents on the grassy upland sheep pastures, as there is no house accommodation. In Funchal many English live in villas, and invalids often live there if a lengthened stay is contemplated. The Portuguese servants are good. The water-supply is occasionally not quite reliable, and all water should be taken boiled for safety. There are four English physicians in Madeira, but no regular closed sanatorium. Hotel prices in Madeira range from Ios. a day down to $f$ Io a month. It is easily reached from Southampton by the Union Castle liners in three and a . half days (first-class return fare, $£ 24$ ), and from Liverpool by the Booth Line in four or five days (return fare, $f, 16$ ).

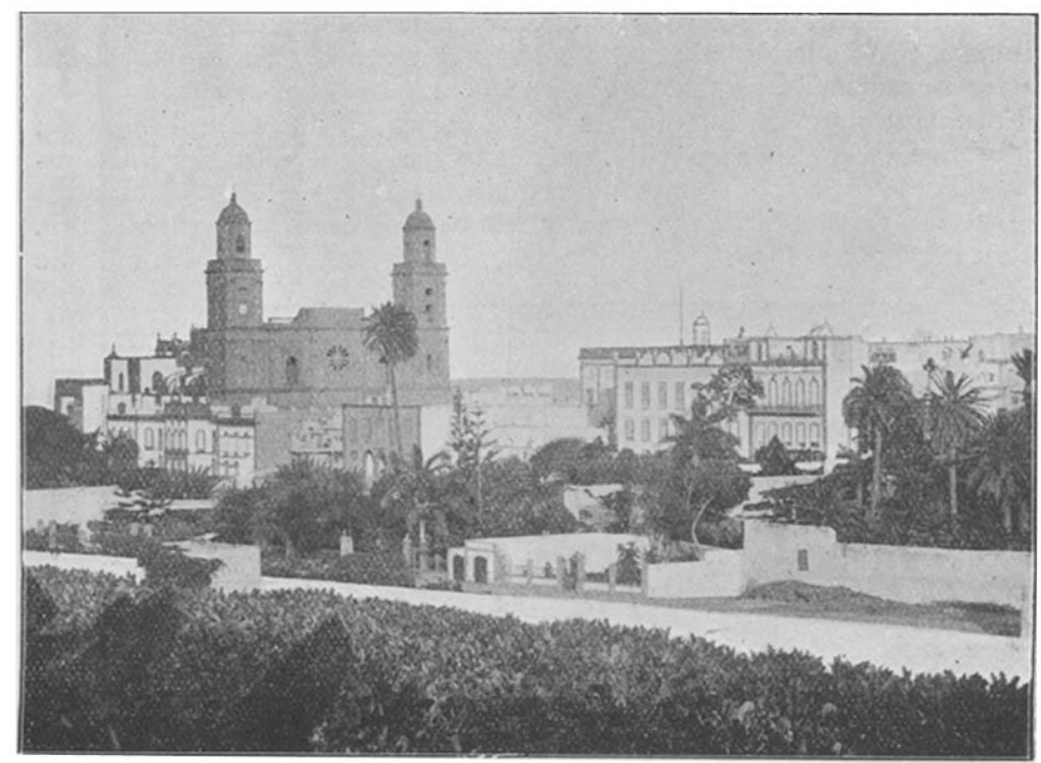

THE CENTRE OF LAS PALMAS.

The Canaries are warmer and drier than Madeira, with more sun, and offer a greater choice of mountain climates. Las Palmas, in Grand Canary, with an average annual rainfall of 9 inches, has a climate approaching the desert type, and Santa Cruz in Teneriffe is similar in its climate, but has not been developed as a health resort. A mile away from Las Palmas the Santa Catalina Hotel was built by an English company in 1890, after the model of Falkenstein Sanatorium, and here I was resident physician for ten years. It was conducted as. an invalids' hotel, not as a strict sanatorium. Architecturally it is perfectly adapted for carrying out the open-air treatment. Fires or artificial heat are quite unnecessary in these islands, so that it is easy to keep patients in the open air day and night without proving too. irksome to their sense of cold. All that is wanted is some wind shelter 
from the northerly trade, and more sun shelter by verandas than is necessary in northern climes. Louvred shutters or persienne are fixed outside the French windows, and when shut can keep out sun or drifting rain while the windows are kept open inside them. There is plenty of English hotel accommodation, the Metropole, like the Catalina, being situated a mile away from the town, and having, similarly, its own system of drainage opening direct into the sea. Villas are not easy to obtain.

The Monte is situated six miles away from Las Palmas at I, $25^{\circ}$ feet altitude, about one hour's drive. The climate is much more bracing, the rainfall greater-about I5 inches annual-and the country is beautiful. This district is admirable for open-air treatment, and

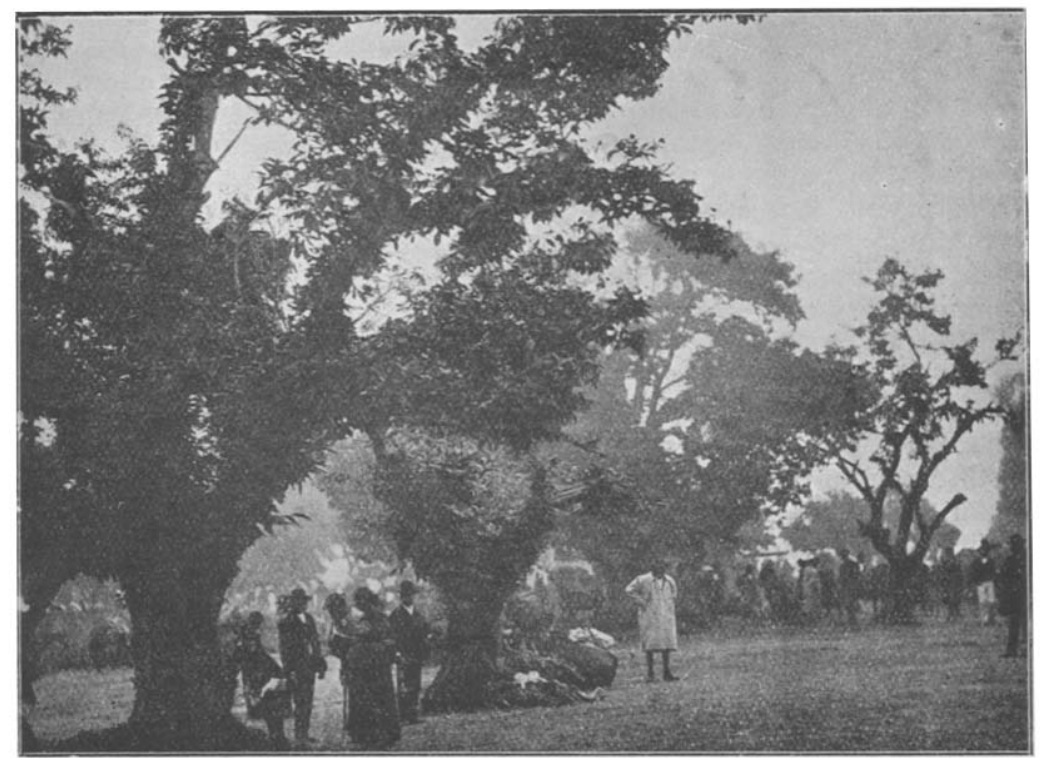

CATTLE MARKET AT TEROR IN THE CHESTNUT WOOD (ALTITUdE. I,800 FEET).

tuberculous patients do very well here, particularly in the spring, summer, and autumn months. There are two English hotels-one first class, surrounded by vineyards. It is a pity there is no accommodation at 3,000 feet altitude at the end of the carriage road. The mountains rise to 6,400 feet fifteen miles from Las Palmas, and are suitable for camping-out on in summer almost to their summits. The climate of Las Palmas is one of the best in the world for rheumatism and arthritis. It is good for bronchitis, but particularly bad for pure spasmodic asthma. The drinking-water supply, having been laid down by an English company in pipes, is the most reliable in the islands. There are three English physicians, an English church, golf links, tennis courts, and cricket ground at Las Palmas.

Oratava is the great health resort in Teneriffe. It is twenty-six miles 
from the port of Santa Cruz by road, but an electric tram runs for three-quarters of the distance, and the rest must be driven. The climate is very similar to that of Grand Canary, but there is more shadowing by cloud, as the trade wind clouds bank up on the north side of the Peak and form a sort of parasol. There is beautiful scenery immediately at the back of Oratava, and one can ride up the Peak through the clouds hanging at about 3,00o feet altitude, and come out above them into an intensely dry and highly actinic atmosphere. The large English Grand Hotel has been taken by a German company, and is now called the Humbolt-Kurhaus. It has a German and two English physicians attached. There are several other hotels, some very cheap in their prices (down to $4 \mathrm{~s}$. 6d. per day).

The south side of Teneriffe, which is warmer, drier, and more sterile, is now provided with good accommodation for invalids at Santa Cruz. A special mention must be made of Güimar, at an elevation of $\mathrm{I}, 200$ feet on the south side of the Peak. It has a very dry sunny climate, and yet is too high up to be enervating. Dr. Salmond has a small but admirable closed sanatorium for consumptives here, with accommodation for ten patients, and there is also a small English hotel in the village, with accommodation for about twenty. This small village community, though isolated from the gaiety which is a marked feature of Las Palmas and Oratava, is an admirable station for the treatment of pulmonary tuberculosis.

There are English hotels also at the altitude stations of Laguna (I,500 feet) and Tacaronte (I,700 feet), and from these two spots some of the most beautiful scenery in the island may be easily reached. The climate is all the year round very good for consumptives. The food-supply in the Canaries is very fair, though the native meat is not equal to the frozen New Zealand. All vegetables, bread, and milk are good, but butter and bacon must be imported from England. Las Palmas is easily reached from Southampton by the Union Castle boats in five days (first-class return, $£ 24$ ), and from Liverpool by the Elder Dempster boats in six days (first-class return, $£(I 5)$. Santa Cruz can be reached by the Union Castle and the New Zealand boats. There are many other boats calling at both ports, for a full list of which the reader is referred to Brown's admirable "Guide to Madeira and the Canaries" (London: Sampson Low and Co.), which will be found a veritable mine of useful information, both general and for invalids. The author is an arrested case of pulmonary tuberculosis who has lived in the islands for the last twenty years.

Brian Melland, M.D. 